\title{
Effects of aripiprazole on pupillometric parameters related to pharmacokinetics and pharmacogenetics after single oral administration to healthy subjects
}

\author{
Dora Koller ${ }^{1}$, Carmen Belmonte ${ }^{1}$, Rubin Lubomirov³ ${ }^{3}$ Miriam Saiz-Rodríguez ${ }^{1}$, Pablo Zubiaur ${ }^{1}$, Manuel Román ${ }^{1,2}$, \\ Dolores Ochoa ${ }^{1,2}$, Antonio Carcas ${ }^{3}$, Aneta Wojnicz ${ }^{1}$, Francisco Abad-Santos ${ }^{1,2}$ \\ ${ }^{1}$ Clinical Pharmacology Department, Hospital Universitario de La Princesa, Instituto Teófilo Hernando, Universidad \\ Autónoma de Madrid, Instituto de Investigación Sanitaria La Princesa (IP), Madrid, Spain \\ ${ }^{2}$ UICEC Hospital Universitario de la Princesa, Plataforma SCReN (Spanish Clinical Research Network), Instituto de \\ Investigación Sanitaria La Princesa (IP), Madrid, Spain. \\ ${ }^{3}$ Pharmacology Department, School of Medicine, Universidad Autónoma de Madrid, Clinical Pharmacology \\ Department, Hospital Universitario La Paz, IdiPAZ, Madrid, Spain.
}

\section{Corresponding author}

Dr. Francisco Abad-Santos

Clinical Pharmacology Department,

Hospital Universitario de la Princesa

Diego de León 62. 28006 Madrid, Spain

Tel: 34 915202425; Fax: 34915202540

E-mail: francisco.abad@salud.madrid.org

\section{Short title}

Aripiprazole influence on pupil contraction

Key words - aripiprazole, pupillometry, pharmacogenetics, pharmacokinetics 


\section{Abstract}

Background: Pupillometry is used for the detection of autonomic dysfunction related to numerous diseases and drug administration. Genetic variants in cytochrome P450 (CYP) (CYP2D6, CYP3A4), dopamine receptor (DRD2, DRD3), serotonin receptor $(H T R 2 A, H T R 2 C)$ and ATP-binding cassette subfamily $\mathrm{B}(A B C B 1)$ genes were previously associated with aripiprazole response.

Aims: Our aim was to evaluate if aripiprazole affects pupil contraction and its relationship with pharmacokinetics and pharmacogenetics.

Methods: Thirty-two healthy volunteers receiving a $10 \mathrm{mg}$ single oral dose of aripiprazole were genotyped for 15 polymorphisms in $A B C B 1, C Y P 2 D 6, D R D 2, D R D 3$, $H T R 2 A$ and HTR2C genes by RT-PCR. Aripiprazole and dehydro-aripiprazole plasma concentrations were measured by HPLC-MS/MS. Pupil examination was performed by automated pupillometry.

Results: Aripiprazole caused pupil constriction and reached the peak value at $\mathrm{C}_{\max }$. HTR2A rs6313 T allele carriers and HTR2C rs3813929 C/T subjects showed higher maximum constriction velocity (MCV) and maximum pupil diameter. Besides, Gly/Gly homozygotes for DRD3 rs6280 showed significantly lower $\mathrm{MCV}$ values. A/G heterozygotes for DRD2 rs6277 showed higher total time taken by the pupil to recover $75 \%$ of the initial resting size values. CYP2D6 intermediate metabolizers showed higher AUC, $\mathrm{C}_{\max }$ and $\mathrm{T}_{1 / 2}$ than extensive metabolizers. $A B C B 1$ G2677T/A A/A homozygotes had greater $\mathrm{T}_{1 / 2}$ in comparison with $\mathrm{C} / \mathrm{C}$ homozygotes. $A B C B 1 \mathrm{C} 3435 \mathrm{~T} \mathrm{~T}$ allele carriers and $\mathrm{C} 1236 \mathrm{~T} \mathrm{C} / \mathrm{T}$ subjects showed greater $\mathrm{AUC}$ than $\mathrm{C} / \mathrm{C}$ homozygotes.

Conclusions: Aripiprazole affects pupil contraction, which could be a secondary effect through dopamine and serotonin receptors. Pupillometry could be a useful tool to assess autonomic nervous system activity during antipsychotic treatment. 


\section{Introduction}

Schizophrenia is a chronic and relapsing disorder with generally incomplete remissions, variable degrees of functional impairment and social disability (Alves et al., 2005). Aripiprazole (ARI) is a quinolinone derivative which belongs to the atypical (second generation) antipsychotics commonly prescribed for patients with acute relapse of schizophrenia or schizoaffective disorders. Doses from 15 to $30 \mathrm{mg}$ once a day are effective and well tolerated by patients (McGavin and Goa, 2002). This drug has partial agonist activity at dopamine D2, D3 and serotonin 5-HT1A receptors, and acts also as 5-HT2A and 5-HT7 receptor antagonist (de Bartolomeis et al., 2015; Lawler et al., 1999; Stip and Tourjman, 2010). The main active metabolite, dehydro-aripiprazole (DARI), amounts to $40 \%$ of the parent compound in plasma, has high affinity towards dopamine D2 receptors and is an antagonist at 5-HT2A receptors. Therefore, DARI has some pharmacological activity similar to ARI (Kirschbaum et al., 2008; Taylor, 2003; Wood et al., 2006).

The metabolism and elimination of ARI is mainly mediated through two cytochrome P450 enzymes, CYP2D6 and CYP3A4. CYP3A4 is responsible for N-dealkylation and both CYP2D6 and CYP3A4 mediate dehydrogenation and hydroxylation of the drug leading to the main metabolite DARI (Kirschbaum et al., 2008; Urichuk et al., 2008). The mean elimination half-life is about 75 hours for ARI, however, for individuals who do not have sufficient CYP2D6 activity (poor metabolizers; PMs), this can be about 146 hours (Dean, 2012a). Approximately 8\% of Caucasians cannot metabolize CYP2D6 substrates and are classified as PMs (Gaedigk et al., 2017). Patients carrying three or more active CYP2D6 alleles (up to 7\% in Caucasians), are called CYP2D6 ultra-rapid metabolizers (UMs) (de Leon et al., 2006; Dean, 2012b). 
Genetic variants of different genes related to ARI response were analysed in previous studies. A1/A1 genotype for DRD2 Taq1A genetic variant (rs1800497) was reported as a predictor of positive symptom improvement on ARI treatment in patients with schizophrenia (Kwon et al., 2008). In case of -141C Ins/Del (rs1799732) polymorphism, Del allele carriers were associated with lower antipsychotic drug response, compared to Ins/Ins genotype (Zhang et al., 2010). Another study showed that Gly/Gly genotype was more common among schizophrenia patients than Ser/Ser genotype for DRD3 Ser9Gly (rs6280) polymorphism in comparison with healthy controls, therefore, Gly/Gly can be considered as a risk factor for the disease (Loch et al., 2015). Moreover, between pediatric patients under antipsychotic treatment the ATP Binding Cassette Subfamily B Member 1 ( $A B C B 1$, coding for P-glycoprotein) $\mathrm{T}$ allele carriers for $\mathrm{G} 2677 \mathrm{~T} / \mathrm{A}$ and C3435T polymorphisms had significantly lower plasma concentration/dose ratio for ARI related to patients with other $A B C B 1$ genotypes (Rafaniello et al., 2017). Furthermore, it was found that subjects carrying G/G genotype for HTR2A A-1438G (rs6311) and $\mathrm{C} / \mathrm{C}$ genotype for $\mathrm{T} 102 \mathrm{C}$ (rs6313) polymorphisms have a poorer ARI response, especially for negative symptoms (Chen et al., 2009). Additionally, carrying the $\mathrm{C}$ allele of HTR2C -759C/T (rs6318) polymorphism was confirmed to influence weight gain following antipsychotic treatment (Ma et al., 2014).

The iris size, and therefore the pupillary diameter, is controlled by two muscles, the sphincter pupillae and the dilator pupillae, which are mainly under the regulation of the parasympathetic nervous system and the sympathetic nervous system, respectively. Contraction of the sphincter, accompanied by the relaxation of the dilator, produces pupil constriction (miosis), while contraction of the dilator, accompanied by the relaxation of the sphincter, produces pupil dilation (mydriasis) (McDougal and Gamlin, 2014). 
Since pupillography was developed in 1958 (Lowenstein and Loewenfeld, 1958), it is used for the detection of autonomic dysfunction associated with numerous diseases, such as diabetes (Piha and Halonen, 1994), heart failure (Keivanidou et al., 2010), Parkinson's disease (Jain et al., 2011), Alzheimer's disease (Fotiou et al., 2000) and hypertension (Koike et al., 2016). Pupillometry is a non-invasive and cost-effective method to determine autonomic nerve activity (Granholm and Steinhauer, 2004). The majority of studies analysing the effect of drugs on the pupil diameter were performed with opioids finding that they cause pupil constriction (miosis) (Harris et al., 2017; Levy-Cooperman et al., 2016; Mangas-Sanjuan et al., 2016; Pickworth et al., 1990). Furthermore, it was shown that carriers of CYP2D6 EM and PM phenotypes treated with tramadol experienced a decrease of response amplitude, constriction velocity and reaction duration as well as an increase of latency of the pupil (Fliegert et al., 2005), however, the effect was minor in subjects carrying PM phenotype.

In a previous study, the refraction and eye anterior segment parameters were investigated in schizophrenic patients under antipsychotic treatment including ARI and healthy controls. Overall, no difference was found in their pupil diameter (Cumurcu et al., 2015). However, in another study it was confirmed that olanzapine causes a decrease in pupil/iris ratio compared to placebo (Kleinloog et al., 2012). Therefore, only two studies were performed to analyse antipsychotic effects on the pupil and only one included ARI. This drug could affect the pupil size due to its partial agonist activity at dopamine D2, D3 and serotonin 5-HT1A receptors, and antagonist activity at 5-HT2A and 5-HT7 receptors (de Bartolomeis et al., 2015; Lawler et al., 1999; Stip and Tourjman, 2010), as it was proved that serotonin and dopamine are effectors on various types of muscles including the sphincter pupillae and the dilator pupillae (Costagliola et al., 2008). Consequently, ARI administration and the presence of polymorphisms in the genes coding for the receptors involved in its mechanism of action may affect the 
response of the pupil.

The aim of the current study was to evaluate if ARI affects various pupillometric parameters in healthy subjects. Furthermore, their connection to pharmacokinetics and pharmacogenetics was also discussed.

\section{Materials and Methods}

\section{Study Population}

A single-dose bioequivalence trial was performed at the Clinical Trial Unit of Hospital de la Princesa (Madrid, Spain) including thirty-six healthy volunteers (18 men and 18 women) who received $10 \mathrm{mg}$ ARI orodispersible tablets. The protocol was approved by the Research Ethics Committee duly authorized by the Spanish Drugs Agency and under the guidelines of good clinical practice. All subjects were adequately informed about the study and, if agreeing to participate, signed an informed consent form before inclusion.

Subjects were included if they met all the inclusion criteria: male and female volunteers, aged between 18 and 55 years, free from any known organic or psychiatric conditions, normal vital signs and electrocardiogram (ECG), normal medical records and physical examination which were relevant to this trial, and no clinically significant abnormalities in haematology, biochemistry, serology and urine tests. Tests monitoring pregnancy and illicit drug use were performed from urine samples and repeated each hospitalisation day before drug administration. Subjects were excluded if they met any of the following criteria: received prescribed pharmacological treatment in the last 15 days or any kind of medication in the last 48 hours prior to receiving the study medication, body mass index (BMI) outside the 18.5-30.0 $\mathrm{kg} / \mathrm{m}^{2}$ range, history of drug allergy, suspected 
consumers of controlled substances, smokers, daily alcohol consumers and/or acute alcohol poisoning in the previous week, having donated blood in the last month, pregnant or breastfeeding women as well as investigational drug study participants in the previous 3 months. Subjects were free to withdraw from the study at any time.

\section{Study design and procedures}

The clinical trial was a phase I, single oral dose, randomized, crossover, two periods, two sequences, open-label, single-centre study with blind determination of the plasma concentrations of ARI and DARI. The volunteers received $10 \mathrm{mg}$ orodispersible ARI tablets. The drug was administered to each healthy volunteer at the same time in each period. Every day the first volunteer received the drug at 9:00 am and the last one at 9:25 am. In the first period, each volunteer received a single dose of one formulation of ARI (test or reference). In the second period, after a washout time frame of 28 days, each volunteer received the same dose of the other formulation. Volunteers fasted from 10 hours before until 5 hours after drug administration. Before drug administration, volunteers rinsed their mouth with $20 \mathrm{ml}$ of water. The reference formulation was Abilify ${ }^{\circledR}$ (Otsuka Pharmaceutical Laboratories Europe, London, United Kingdom).

Twenty blood samples were collected from baseline (before administration) until $72 \mathrm{~h}$ after dosing. Samples were centrifuged at $3500 \mathrm{rpm}(1900 \mathrm{G})$ for 10 minutes and then the plasma was collected and stored at $-20^{\circ} \mathrm{C}$ until the determination of plasma concentrations by the analytical laboratory. 


\section{Plasma concentrations of aripiprazole and dehydro-aripiprazole}

Plasma concentrations of ARI and DARI were measured by high-performance liquid chromatography tandem mass spectrometry (HPLC-MS/MS) method validated in our laboratory (Wojnicz et al., 2017), with a lower limit of quantification of $0.18 \mathrm{ng} / \mathrm{mL}$ for ARI and $0.35 \mathrm{ng} / \mathrm{mL}$ for DARI. Stable isotope labelled ARI (ARI-D8) was used as an internal standard for both analytes. For analyte extraction we used three-step microelution-solid-phase extraction (Oasis PRiME HLB 96-well $\mu$ Elution Plate) from $200 \mu \mathrm{L}$ of human plasma. An octadecyl carbon chain (C18)-bonded silica, reversed phase HPLC column with pentafluorophenyl ligand (to ensure extra selectivity), was used for chromatographic separation. A combination of ammonium formate in Milli-Q water $(5 \mathrm{mM} ; \mathrm{pH} 4.0)$ and acetonitrile $(65: 35, \mathrm{v} / \mathrm{v})$ was used as the mobile phase at a flow rate of $0.6 \mathrm{~mL} / \mathrm{min}$. The total chromatographic run time was 8 minutes, constituting of a 5-minute run time and a 3-minute re-equilibration time. Overall, a volume of $5 \mu \mathrm{L}$ eluent was injected into the HPLC/MS/MS system. Linearity was confirmed for concentration ranges from 0.18 to $110 \mathrm{ng} / \mathrm{mL}$ for ARI and 0.35 to 100 $\mathrm{ng} / \mathrm{mL}$ for DARI.

\section{Pharmacokinetic Assessments}

Pharmacokinetic parameters were calculated by non-compartmental analysis using WinNonlin Professional (Version 2.0, Pharsight Corporation, Palo Alto, California). The maximum plasma concentration $\left(\mathrm{C}_{\max }\right)$ and the elapsed time to reach the maximum plasma concentration $\left(\mathrm{T}_{\max }\right)$ were obtained directly from raw data. The total area under the curve (AUC) from administration to infinity $\left(\mathrm{AUC}_{0-\infty}\right)$ was calculated as the sum of $\mathrm{AUC}_{0-\mathrm{t}}$ and the residual area $\left(\mathrm{C}_{\mathrm{t}}\right.$ divided by $\mathrm{k}_{\mathrm{e}}$, with $\mathrm{C}_{\mathrm{t}}$ as the last measured concentration and $\mathrm{k}_{\mathrm{e}}$ as the apparent terminal elimination rate, which was estimated by log-linear regression from the terminal portion of the log-transformed concentration- 
time plots). Half-life was calculated by dividing 0.693 by $\mathrm{k}_{\mathrm{e}}$. The total drug clearance adjusted for bioavailability $(\mathrm{Cl} / \mathrm{F})$ was calculated by dividing the dose by the $\mathrm{AUC}_{0-\infty}$ and adjusting for weight. Volume of distribution adjusted for bioavailability ( $\mathrm{Vd} / \mathrm{F})$ was calculated as $\mathrm{Cl} / \mathrm{F}$ divided by ke. The $\mathrm{AUC}$ and $\mathrm{C}_{\max }$ were adjusted for dose and weight (AUC/dW and $\mathrm{C}_{\max } / \mathrm{dW}$ ) and logarithmically transformed for statistical analysis.

For DARI, only $\mathrm{AUC}_{0-\mathrm{t}}$ (truncated to 72 hours), $\mathrm{C}_{\max }$ and $\mathrm{T}_{\max }$ were determined, because it was not possible to calculate the remaining parameters.

\section{Pupillary light reflex (PLR) measurements}

Pupillometric measurements were performed before drug administration and 2, 4, 6, 8, 10, and 12 hours after drug administration recorded with a PRL 200 automated monocular infrared pupillometer (NeurOptics, Irvine, CA, United States). Each measurement was performed in a hospital room with artificial illumination. Before starting the measurement, the subject was instructed to focus on a small target object - a wall chart - that was at least 3 meters away with the eye that was not being tested open (left eye). Stimuli were single light pulses with a fixed intensity of $180 \mu \mathrm{W}$ (microwatts) during 154 milliseconds. Visual light stimuli were generated using white light emitting diodes (LED) monocularly. The LED lightning source was placed approximately $2 \mathrm{~cm}$ away from the right eye and its largeness was $5 \times 5 \mathrm{~mm}$. Once the device was focused on the target pupil (right eye), a white light stimulus was flashed. The measurements were sampled at a frequency of 32-frames per second and lasted up to 5 seconds, allowing a full or partial recovery of the pupil size after light constriction. The above conditions were identical for all subjects to keep the measurements comparable. Additionally, it was of importance that the eye cup of the pupillometer was correctly fitted as it helps to reduce the possibility of stray light entering the eye during 
measurements. In order to adjust for the potential differences in luminosity, consequently in maximum pupil diameter, a digital light (lux) meter (PCE Iberica, S.L., Albacete, Spain) was used to measure the light intensity in lux immediately before each analysis. Light intensity was $96.08 \pm 76.89 \mathrm{lux}\left(\mathrm{lm} / \mathrm{m}^{2}\right)$.

We monitored 8 different pupillometric parameters as described in the user guide (NeurOptics, Inc., 2010). Maximum pupil diameter (MAX) and minimum pupil diameter (MIN) represent the pupil diameter before the constriction and just at the peak of the constriction, respectively. $\mathrm{CON}$ is the percent of the constriction calculated by $(\mathrm{MAX}-\mathrm{MIN}) / \mathrm{MAX}$. LAT is the latency and it represents the time of the onset of the constriction. ACV and $\mathrm{MCV}$ are the average and the maximum constriction velocity, respectively. The negative sign is to differentiate constriction from dilation, which is the opposite movement. ADV is the average dilation velocity and represents the average pupillary velocity, when, after reaching its constriction, the pupil tends to recover and dilates back to its initial resting size. T75 is the total time taken by the pupil to recover $75 \%$ of the initial resting pupil size after it reached the peak of constriction.

\section{Genotyping}

DNA was extracted from $1 \mathrm{ml}$ peripheral blood samples using a MagNA Pure LC DNA Isolation Kit in an automatic DNA extractor (MagNa Pure ${ }^{\circledR}$ System, Roche Applied Science, Indianapolis, Indiana) and quantified spectrophotometrically in a NanoDrop ${ }^{\circledR}$ ND-1000 Spectrophotometer (Nanodrop Technologies, Wilmington, Delaware).

The CYP2D6 *3, *4 and *5 polymorphisms were analysed by RT-PCR using LightCyler® 2.0 instrument (RocheDiagnostics, Mannheim, Germany). The primers and the probes were designed by TIB MOLBIOL (Berlin, Germany) for this purpose. 
$A B C B 1$ C3435T, C1236T, G2677T/A, DRD2 rs6277, rs1800497, DRD3 rs6280, CYP2D6 *6, *7 and *9, HTR2A rs6313, rs6314 and HTR2C rs3813929 polymorphisms were genotyped using a StepOnePlus ${ }^{\mathrm{TM}}$ PCR instrument (Applied Biosystems, Foster City, California). To determine the copy number variations (CNVs) in the CYP2D6 gene a TaqMan Copy Number Assay (Applied Biosystems, Foster City, California) was used, which detects a specific sequence on exon 9. For statistical reasons, all the samples were run in quadruplicates in the instrument. A positive control was used from Coriell Institute with a known copy number of CYP2D6 (3 copies, Coriell ID: NA17221). The assay was performed with an endogenous control, TaqManRNase P Copy Number Reference Assay (Applied Biosystems, Foster City, California). To determine the exact number of CYP2D6 copies we used CopyCaller Software (Applied Biosystems, Foster City, California) that uses the comparative $\Delta \Delta \mathrm{CT}$ method (Schmittgen and Livak, 2008).

\section{Statistical analysis}

Statistical analysis was performed with the SPSS 19.0 software (SPSS Inc., Chicago, Illinois). P values lower or equal than 0.05 were considered significant. The HardyWeinberg equilibrium was estimated for all analysed variants. Deviations from the equilibrium were detected by comparing the observed and expected frequencies using a Fisher exact test based on the De Finetti program (available at http://ihg.gsf.de/cgibin/hw/hwa1.pl).

The changes between the recorded values in different time points in pupillometric parameters (MAX, MIN, T75, MCV, CON, ACV, ADV, LAT) after the administration of ARI were analysed by repeated measures ANOVA. The values were adjusted for 
differences in light intensity immediately before each analysis. Differences in pharmacokinetic and pupillometric parameters between individuals with distinct genotypes were statistically analysed by a parametric univariate analysis ( $t$-test or ANOVA). A simple linear regression was performed to predict pupillometric parameters based on pharmacokinetic data (AUC, $\mathrm{C}_{\max }, \mathrm{T}_{1 / 2}, \mathrm{~T}_{\max }$ ). Multiple linear regression models were used to study factors related to all the pupillometric and pharmacokinetic dependent variables. Models for each dependent with standardized $(\beta)$ regression coefficients are shown in results. CYP2D6 genotypes were classified in 4 phenotypes (PM, intermediate metabolizer: IM, extensive (normal) metabolizer: EM, and UM) according to the method used by Gaedigk et al., which is based on the functionality of alleles (Gaedigk et al., 2008), but PM and UM were not found in this study.

\section{Results}

\section{Demographic and genotypic characteristics}

Thirty-six healthy volunteers were included in the bioequivalence study. All of them completed it, however, only 32 (17 men and 15 women) participated in the pharmacogenetic and the pupillometric analyses. Average age was distinctively different between men and women, but it did not reach the significant level $(25.6 \pm 7.0$ years and $31.0 \pm 10.7$ years, respectively, $p=0.06)$. Notably, men had greater weight than women $(77.4 \pm 8.7 \mathrm{~kg}$ and $62.4 \pm 8.8 \mathrm{~kg}$, respectively, $\mathrm{p}<0.001)$, but the BMI values did not differ significantly $\left(25.5 \pm 2.2 \mathrm{~kg} / \mathrm{m}^{2}\right.$ and $23.8 \pm 3.5 \mathrm{~kg} / \mathrm{m}^{2}$, respectively, $\mathrm{p}=0.06)$. All the subjects were Caucasian. 
The genotype frequencies of the analysed genes are shown in Table 1. All genetic variants were in Hardy-Weinberg equilibrium $(\mathrm{p} \geq 0.05)$. Differences in genotype frequencies were found between men and women in CYP2D6 phenotype and DRD2 rs6277 and HTR2C rs3813929 polymorphisms, as shown in Table 1. In case of HTR2C rs3813929 polymorphism, it is explained by the location of the gene on chromosome X.

Table 1. Genotype frequencies of the analysed polymorphisms. Values are expressed as number of subjects (percentage from the total).

\begin{tabular}{|c|c|c|c|c|}
\hline Gene / variant & Genotype & Total & Men & Women \\
\hline \multirow{2}{*}{$\begin{array}{l}\text { CYP2D6 PHENOTYPE } \\
(\mathrm{N}=32)\end{array}$} & IM & $13(39.4)$ & $4(30.8)$ & $9(69.2)$ \\
\hline & EM & $19(60.6)$ & $13(68.4)$ & $6(32.5)^{*}$ \\
\hline \multirow[t]{3}{*}{$A B C B 1 / \mathrm{C} 3435 \mathrm{~T}(\mathrm{~N}=32)$} & $\mathrm{C} / \mathrm{C}$ & $7(21.8)$ & $5(23.8)$ & $2(28.6)$ \\
\hline & $\mathrm{C} / \mathrm{T}$ & $16(50.0)$ & $10(47.6)$ & $6(37.5)$ \\
\hline & $\mathrm{T} / \mathrm{T}$ & $9(28.2)$ & $6(28.6)$ & $3(33.3)$ \\
\hline \multirow{3}{*}{$\begin{array}{c}A B C B 1 / C 1236 \mathrm{~T} \\
(\mathrm{~N}=32)\end{array}$} & $\mathrm{C} / \mathrm{C}$ & $13(40.6)$ & $7(41.2)$ & $6(40.0)$ \\
\hline & $\mathrm{C} / \mathrm{T}$ & $15(46.9)$ & $8(47.1)$ & $7(46.7)$ \\
\hline & $\mathrm{T} / \mathrm{T}$ & $4(12.5)$ & $2(11.8)$ & $2(13.3)$ \\
\hline \multirow{4}{*}{$\begin{array}{c}A B C B 1 / \mathrm{G2677T} / \mathrm{A} \\
(\mathrm{N}=32)\end{array}$} & $\mathrm{C} / \mathrm{C}$ & $11(34.4)$ & $6(35.3)$ & $5(33.3)$ \\
\hline & $\mathrm{C} / \mathrm{A}$ & $15(46.9)$ & $8(47.1)$ & $7(46.7)$ \\
\hline & $\mathrm{C} / \mathrm{T}$ & $2(6.25)$ & $1(5.88)$ & $1(6.67)$ \\
\hline & $\mathrm{A} / \mathrm{A}$ & $4(12.5)$ & $2(11.8)$ & $2(13.3)$ \\
\hline \multirow[t]{3}{*}{ DRD2/ rs6277 (N=32) } & $\mathrm{A} / \mathrm{A}$ & $9(28.1)$ & $3(17.6)$ & $6(40.0)$ \\
\hline & $\mathrm{A} / \mathrm{G}$ & $17(53.1)$ & $8(47.1)$ & $9(60.0)$ \\
\hline & $\mathrm{G} / \mathrm{G}$ & $6(18.8)$ & $6(35.3)$ & $0(0.0)^{*}$ \\
\hline \multirow{3}{*}{$\begin{array}{c}D R D 2 / \text { rs1800497 } \\
(\mathrm{N}=32)\end{array}$} & A1/A1 & $1(3.1)$ & $0(0.0)$ & $1(6.67)$ \\
\hline & A1/A2 & $8(25.0)$ & $4(23.5)$ & $4(26.7)$ \\
\hline & $\mathrm{A} 2 / \mathrm{A} 2$ & $23(71.9)$ & $13(76.5)$ & $10(66.7)$ \\
\hline \multirow[t]{3}{*}{$D R D 3 / \operatorname{rs} 6280(\mathrm{~N}=32)$} & Ser/Ser & $11(34.3)$ & $6(35.3)$ & $5(33.3)$ \\
\hline & Ser/Gly & $17(53.1)$ & $9(52.9)$ & $8(53.3)$ \\
\hline & Gly/Gly & $4(12.5)$ & $2(11.8)$ & $2(13.3)$ \\
\hline$H T R 2 A / \operatorname{rs} 6313(\mathrm{~N}=32)$ & $\mathrm{C} / \mathrm{C}$ & $11(34.4)$ & $4(23.5)$ & $7(46.7)$ \\
\hline
\end{tabular}




\begin{tabular}{c|cccc} 
& $\mathrm{C} / \mathrm{T}$ & $11(34.4)$ & $5(29.4)$ & $6(40.0)$ \\
& $\mathrm{T} / \mathrm{T}$ & $10(31.3)$ & $8(47.1)$ & $2(13.3)$ \\
$\boldsymbol{H}$ & & & & \\
& $\mathrm{C} / \mathrm{C}$ & $25(78.1)$ & $13(76.5)$ & $12(80.0)$ \\
$\boldsymbol{H} \mathbf{H T R 2 C / ~ r s 3 8 1 3 9 2 9}$ & $\mathrm{C} / \mathrm{T}$ & $7(21.9)$ & $4(23.5)$ & $3(20.0)$ \\
$(\mathbf{N = 3 2 )}$ & $\mathrm{C} / \mathrm{C}$ & $20(62.5)$ & $13(23.5)$ & $7(46.7)$ \\
& $\mathrm{C} / \mathrm{T}$ & $7(21.9)$ & $0(0.0)$ & $7(40.0)^{*}$ \\
& $\mathrm{~T} / \mathrm{T}$ & $5(15.6)$ & $4(47.1)$ & $1(13.3)$
\end{tabular}

* $\mathrm{P}<0.05$ versus men. Abbreviations: $A B C B 1$ : ATP binding cassette subfamily $\mathrm{B}$ member 1 ; CYP: cytochrome p450 oxidase; HTR2A: serotonin receptor $2 \mathrm{~A}$; HTR2C: serotonin receptor $2 \mathrm{C}$; DRD2: dopamine D2 receptor; DRD3: dopamine D3 receptor; IM: intermediate metabolizer; EM: extensive metabolizer.

\section{Pharmacokinetic analysis}

Mean and standard deviation (SD) of ARI and DARI pharmacokinetic parameters are shown in Table 2. After adjusting for weight, sex differences were found in ARI Vd/F $(\mathrm{p}=0.01)$ and in $\mathrm{Cl} / \mathrm{F}(\mathrm{p}=0.01)$ as women had higher and lower level than men, respectively. Women showed higher $\mathrm{T}_{1 / 2}, \mathrm{C}_{\max }$ and $\mathrm{AUC}_{0-\mathrm{t}}(\mathrm{p}<0.05)$, but these differences disappeared after adjusting for weight. No differences were found between sexes in DARI pharmacokinetics.

Table 2. Aripiprazole and dehydro-aripiprazole pharmacokinetic parameters after a single oral dose of $10 \mathrm{mg}$.

\begin{tabular}{c|ccc} 
Aripiprazole & All & Men & Women \\
\hline $\mathbf{A U C}_{\mathbf{0}-72}(\mathbf{n g} \cdot \mathbf{h} / \mathbf{m L})$ & $1570.0 \pm 335.6$ & $1441.1 \pm 255.9$ & $1698.9 \pm 371.5$ \\
$\mathbf{C}_{\mathbf{M A X}}(\mathbf{n g} / \mathbf{m L})$ & $48.1 \pm 9.7$ & $44.7 \pm 8.6$ & $51.6 \pm 9.4$ \\
$\mathbf{T}_{\mathbf{M A X}}(\mathbf{h})$ & $2.9 \pm 1.7$ & $2.8 \pm 1.7$ & $3.0 \pm 1.7$ \\
$\mathbf{T}_{1 / 2}(\mathbf{h})$ & $58.3 \pm 30.0$ & $48.7 \pm 29.0$ & $67.9 \pm 28.6$ \\
\end{tabular}




\begin{tabular}{|c|c|c|c|}
\hline Vd/F (L/kg) & $4.45 \pm 0.80$ & $4.07 \pm 0.50$ & $4.81 \pm 0.90 *$ \\
\hline $\mathrm{Cl} / \mathbf{F}(\mathbf{m L} / \mathbf{h} \cdot \mathbf{k g})$ & $60.0 \pm 20.0$ & $70.0 \pm 20.0$ & $50.0 \pm 20.0 *$ \\
\hline \multicolumn{4}{|l|}{ Dehydro-aripiprazole } \\
\hline $\operatorname{AUC}_{0-72}(\mathrm{ng} \cdot \mathbf{h} / \mathrm{mL})$ & $376.6 \pm 136.2$ & $389.7 \pm 145.9$ & $363.4 \pm 128.7$ \\
\hline $\mathrm{C}_{\text {MAX }}(\mathrm{ng} / \mathrm{mL})$ & $6.6 \pm 2.3$ & $6.7 \pm 2.5$ & $6.4 \pm 2.1$ \\
\hline $\mathbf{T}_{\text {MAX }}(\mathbf{h})$ & $49.6 \pm 19.0$ & $46.7 \pm 20.5$ & $52.6 \pm 17.3$ \\
\hline
\end{tabular}

$* \mathrm{P} \leq 0.05$ versus men after adjusting for weight.

Abbreviations: $\mathrm{C}_{\max }$ : maximum plasma concentration; $\mathrm{T}_{\max }$ : time to reach the maximum plasma concentration; $\mathrm{AUC}_{0-}$ 72: area under the curve between 0 and $72 \mathrm{~h}$ after dosing; $\mathrm{T}_{1 / 2}$ : half-life; $\mathrm{Cl} / \mathrm{F}$ : total drug clearance adjusted for bioavailability; $\mathrm{Vd} / \mathrm{F}$ : volume of distribution adjusted for bioavailability.

\section{The effect of aripiprazole on pupillometry and its relationship with pharmacokinetics}

Following oral administration of ARI, significant decrease was observed at $2 \mathrm{~h}$ in pupillary parameters MAX, MIN, T75 and MCV, therefore, the pupil showed constriction. The changes reached their peak value at 2-4 hours after drug administration, concurrently when ARI reached the maximum concentration of 48 $\mathrm{ng} / \mathrm{mL}\left(\mathrm{C}_{\max }\right)$ at $2.9 \mathrm{~h}\left(\mathrm{~T}_{\max }\right)$. Thereafter, they started to increase linearly in time until the last measurement point (12 h). (Figure 1). No differences were found between men and women in any of these pupillometric parameters.

Mean and SD of baseline, $2 \mathrm{~h}$ after drug administration and maximum values of the pupillometric parameters are shown in Table 3. 
Table 3. Pupillometric parameters before and after administration of aripiprazole $10 \mathrm{mg}$. Values are expressed as mean $\pm \mathrm{SD}$.

\begin{tabular}{c|cccc}
$\begin{array}{c}\text { Pupillometric } \\
\text { parameters }\end{array}$ & $\begin{array}{c}\text { Baseline } \\
\text { value (0h) }\end{array}$ & $\mathbf{2 h}$ & $\begin{array}{c}\text { Last measured } \\
\text { value (12h) }\end{array}$ & $\begin{array}{c}\text { Partial eta } \\
\text { squared }\end{array}$ \\
\hline MAX (mm) & $5.00 \pm 0.84$ & $4.30 \pm 1.01^{* *}$ & $5.80 \pm 0.88^{* *}$ & 0.59 \\
MIN (mm) & $3.41 \pm 0.69$ & $3.03 \pm 0.75^{*}$ & $4.16 \pm 0.86^{*}$ & 0.56 \\
T75 (s) & $1.52 \pm 0.60$ & $1.25 \pm 0.60^{* *}$ & $1.64 \pm 0.63$ & 0.12 \\
MCV (mm/s) & $-4.88 \pm 0.74$ & $-4.17 \pm 1.02^{* *}$ & $-4.74 \pm 0.71^{*}$ & 0.26 \\
ACV (mm/s) & $-3.79 \pm 0.59$ & $-3.20 \pm 0.79$ & $-3.71 \pm 0.55$ & 0.14 \\
CON (\%) & $-29 \pm 0.04$ & $-26 \pm 0.05$ & $-27 \pm 0.06$ & 0.06 \\
ADV (mm/s) & $1.00 \pm 0.28$ & $0.90 \pm 0.31$ & $1.00 \pm 0.22$ & 0.08 \\
LAT (s) & $0.20 \pm 0.02$ & $0.20 \pm 0.03$ & $0.20 \pm 0.02$ & 0.04 \\
\hline
\end{tabular}

Abbreviations: MAX: maximum pupil diameter; MIN: minimum pupil diameter; CON: percent of the constriction; LAT: latency; ACV: average constriction velocity; MCV: maximum constriction velocity; ADV: dilation velocity; T75: total time taken by the pupil to recover $75 \%$ of the initial resting pupil size after it reached the peak of constriction. $* p \leq 0.05$ related to the baseline value. $* * p \leq 0.001$ related to the baseline value.

Moreover, $\mathrm{C}_{\max }$ and $\mathrm{T}_{1 / 2}$ had influence on $\mathrm{MAX}$ and MIN pupillometric parameters. When MAX was estimated, it was found that it has an indirect relationship with $\mathrm{T}_{1 / 2}$ (non-standardized $\beta$ coefficient $=-0.01, \mathrm{p}=0.02, \mathrm{r}^{2}=0.16$, Cohen's $\mathrm{f}^{2}=0.19$ ). However, no significant effect was found with $C_{\max }$ (non-standardized $\beta$ coefficient $=$ $0.04, p=0.09, r^{2}=0.10$, Cohen's $\left.f^{2}=0.11\right)$. Regarding MIN, we detected the same tendency: an indirect relationship with $\mathrm{T}_{1 / 2}$, (non-standardized $\beta$ coefficient $=-0.01, \mathrm{p}=$ $0.01, \mathrm{r}^{2}=0.18$, Cohen's $\mathrm{f}^{2}=0.22$ ), however, $\mathrm{C}_{\max }$ did not reach the statistically significant level (non-standardized $\beta$ coefficient $=-0.01, \mathrm{p}=0.10, \mathrm{r}^{2}=0.02$, Cohen's $\mathrm{f}^{2}$ $=0.01)$. No interrelation was found with the remaining parameters. Moreover, after analysing heart rate variability as another marker of autonomic function, no association was found with the pupillometric parameters at different time points. 


\section{The influence of polymorphisms on pupillometry}

TT subjects for the rs6313 SNP in HTR2A gene showed higher MCV $\left(\mathrm{p}=0.001, \mathrm{r}^{2}=\right.$ 0.399, Cohen's $\left.\mathrm{f}^{2}=0.664\right)$ and MAX $\left(\mathrm{p}=0.030, \mathrm{r}^{2}=0.226\right.$, Cohen's $\left.\mathrm{f}^{2}=0.292\right)$ (Figure

2). Furthermore, carriers of T allele for the rs3813929 of HTR2C showed higher T75 (p $=0.044, \mathrm{r}^{2}=0.131$, Cohen's $\left.\mathrm{f}^{2}=0.151\right)$, but this effect disappeared after Bonferroni correction $(\mathrm{p}=0.078)$. Additionally, the multivariate analysis revealed that TT subjects for this SNP show higher MAX $\left(p=0.008, r^{2}=0.214\right.$, Cohen's $\left.f^{2}=0.272\right)$ and MCV $(p$ $=0.000, \mathrm{r}^{2}=0.348$, Cohen's $\left.\mathrm{f}^{2}=0.534\right)$ values. Besides, carriers of Gly/Gly genotype for DRD3 rs6280 SNP showed significantly lower MCV values $\left(\mathrm{p}=0.013, \mathrm{r}^{2}=0.474\right.$, Cohen's $\left.\mathrm{f}^{2}=0.901\right)$. Additionally, AG heterozygotes for DRD2 rs6277 SNP showed higher T75 values $\left(\mathrm{p}=0.047, \mathrm{r}^{2}=0.125\right.$, Cohen's $\left.\mathrm{f}^{2}=0.143\right)$.

However, polymorphisms in $A B C B 1$ (C3435T, C1236T, G2677T/A) and DRD2 (rs1800497) genes and CYP2D6 phenotypes had no influence on pupillometric parameters.

\section{Pharmacokinetics and polymorphisms}

Bivariate and multivariate analyses revealed associations between several pharmacokinetic parameters and polymorphisms in the analysed genes. CYP2D6 intermediate metabolizers (IM) showed higher AUC $\left(\mathrm{p}=0.010, \mathrm{r}^{2}=0.198\right.$, Cohen's $\mathrm{f}^{2}=$ 0.247), $\mathrm{C}_{\max }\left(\mathrm{p}=0.012, \mathrm{r}^{2}=0.187\right.$, Cohen's $\left.\mathrm{f}^{2}=0.230\right)$ and $\mathrm{T}_{1 / 2}\left(\mathrm{p}=0.041, \mathrm{r}^{2}=0.128\right.$, Cohen's $\mathrm{f}^{2}=0.147$ ) than extensive metabolizers (EM) (Figure 3). Moreover, G2677T/A polymorphism in $A B C B 1$ gene had an influence on the $\mathrm{T}_{1 / 2}$ of ARI, but it was only significant in the multivariate analysis (bivariate analysis: $\mathrm{p}=0.055, \mathrm{r}^{2}=0.181$, Cohen's $\mathrm{f}^{2}=0.221$; multivariate analysis: non-standardized $\beta$ coefficient $=0.35 ; \mathrm{p}=0.040, \mathrm{r}^{2}=$ 0.243 , Cohen's $\left.\mathrm{f}^{2}=0.321\right)$ as $\mathrm{A} / \mathrm{A}$ homozygotes had greater value $(74.9 \pm 39.8)$ in 
comparison with $\mathrm{C} / \mathrm{C}$ homozygotes $(40.4 \pm 10.0)$. The minor allele carriers $(\mathrm{C} / \mathrm{T}$ and $\mathrm{T} / \mathrm{T})$ of C3435T polymorphism showed greater AUC $\left(\mathrm{p}=0.074, \mathrm{r}^{2}=0.164\right.$, Cohen's $\mathrm{f}^{2}$ $=0.196)$ in the univariate analysis, although they did not reach statistical significance. However, in the multivariate analysis, this reached a statistically significant level (nonstandardized $\beta$ coefficient $=0.33 ; \mathrm{p}=0.045, \mathrm{r}^{2}=0.337$, Cohen's $\mathrm{f}^{2}=0.508$ ). Moreover, it revealed that heterozygote $\mathrm{CT}$ subjects for C1236T SNP had also higher level of AUC (non-standardized $\beta$ coefficient $=0.39 ; \mathrm{p}=0.019, \mathrm{r}^{2}=0.234$, Cohen's $\mathrm{f}^{2}=0.305$ ) (Figure 3). No association was found between DARI and the polymorphisms of $C Y P 2 D 6$ or $A B C B 1$.

\section{Discussion}

\section{Sex Influence on Pharmacokinetics}

ARI pharmacokinetics is affected by sex based on a previous study performed by our group as $\mathrm{AUC}, \mathrm{C}_{\max }, \mathrm{T}_{1 / 2}$, and $\mathrm{Vd} / \mathrm{F}$ were higher in women than in men (Belmonte et al., 2016). In the current analysis, these results were verified and additionally $\mathrm{Cl} / \mathrm{F}$ was lower in women than in men. These findings are consistent with previous studies (Islam et al., 2017; Schwartz, 2003). However, they are mostly explained by differences in body weight as it is shown in the drug label. It states that $\mathrm{C}_{\max }$ and $\mathrm{AUC}$ of aripiprazole are $30-40 \%$ higher in women than in men (Abilify, Otsuka Pharmaceutical, Co., Ltd., 2014). Sex-related variability in pharmacokinetics of psychotropic drugs can be due to the differences in gastric acidity, intestinal motility, body weight and composition, blood volume, liver enzymes (mainly the cytochrome P450), renal excretion or the sensitivity to side effects and toxicity of drugs (Marazziti et al., 2013). 


\section{Pharmacokinetics and pupillometry}

Pupillary dilation as a marker of drug occupancy and action has been measured several times in previous studies (Graur and Siegle, 2013; Siepmann et al., 2007). However, mostly the effects of opioid drugs were analysed. Miosis is thought to be caused by a direct opioid effect during the use of these drugs on $\mu$ receptors in the autonomic nucleus of the oculomotor nerve (Larson et al., 1997). In addition to agonist activity at the $\mu$-opioid receptor, tramadol, an opioid drug used during acute or chronic pain, also inhibits the re-uptake of the neurotransmitters norepinephrine and serotonin (5-HT) in the descending inhibitory pain pathways, thus, facilitating 5-HT release (Raffa et al., 1992). Based on this information, as ARI has antagonist activity at 5-HT2A and 5-HT7 receptors, we suspected that the drug has a similar effect on the pupil as tramadol has.

According to our knowledge, antipsychotic effects on pupillary motility was explored only in patients treated with olanzapine, where it caused a decrease in pupil/iris ratio (Kleinloog et al., 2012). In another study, antipsychotic drugs (risperidone, olanzapine, aripiprazole, amilsulpiride, clozapine, quetiapine and ziprasidone) did not cause a change in pupil diameter compared with placebo (Cumurcu et al., 2015).

The pupillary parameters MAX, MIN, MCV and T75 significantly changed after 2-4 hours of drug administration, exactly when ARI reached $\mathrm{C}_{\max }$. The background of these changes could be rooted in the fact that serotonin is an effector on various types of smooth muscles, functioning also at the level of ciliary muscle and sphincter of the pupil (Costagliola et al., 2008). Serotonin and its receptors 5-HT1A and 5-HT2A are proved to be abundantly expressed in mammalian iris-ciliary body complex (ICB) (Barnett and Osborne, 1993a; Tobin et al., 1988; Tobin and Osborne, 1989). Additionally, it is known that higher levels of serotonin causes pupil dilation when it 
binds to its receptors (Yu et al., 2004). Moreover, dopamine can cause pupil dilation or constriction through sympathetic and parasympathetic nerves, respectively (Spiers and Calne, 1969). Based on our results, pupil constriction could be due to the partial antagonist activity of ARI at 5-HT2A and 5-HT7 receptors, because ARI is a partial agonist at dopamine receptors, therefore, it would cause dilated pupils. Therefore, clinicians could assess autonomic nervous system activity in schizophrenic patients treated with antipsychotic drugs. This would allow to estimate subclinical signs with a non-invasive method like pupillometry.

\section{Polymorphisms and pupillometry}

So far only a few related studies were carried out to analyse the relationship between pupil miosis and mydriasis in response to drugs and genetic polymorphisms. When evaluating the effects of the CYP2D6 gene duplication on the pharmacokinetics and pharmacodynamics of tramadol, the mean maximal decrease speed in pupil diameter was 1.5-fold longer in UMs compared with EMs (Fliegert et al., 2005). In contrast, in our study, no association was found between CYP2D6 phenotypes when analysing ARI pharmacokinetics and the pupillometric parameters. Therefore, the effect of CYP2D6 on the pupil was not measurable. Additionally, probably due to the low sample size, we could not find UM and PM among the studied group.

No $A B C B 1$ genetic variants were found which could predict pupil miotic and mydriatic effects while administrating the opioid drug loperamide (Skarke et al., 2003). To the extent of our knowledge, no other study was carried out to analyse the genetic differences in $A B C B 1$ related to pupil contraction. We could not associate C3435T, C1236T and G2677T/A polymorphisms in the gene with any of the pupillometric parameters. Second-generation antipsychotics such as amisulpride, aripiprazole, 
risperidone and paliperidone are transported by P-gp (Moons et al., 2011). A P-gp inhibitor, HM30181, increases the oral bioavailability of co-administered drugs (Kim et al., 2014, p. 30; Kwak et al., 2010). Pupil diameter was slightly decreased or remained almost the same over time when loperamide was administered alone or co-administered with HM30181, respectively, whereas it was markedly decreased when quinidine -a CYP2D6 inhibitor- was co-administered, suggesting that the influence of P-gp could be minor compared to CYP2D6 (Kim et al., 2014, p. 30; Skarke et al., 2003).

It is known that dopamine administration produces marked dilatation of the pupil (Ong and Bruning, 1981; Spiers and Calne, 1969). The administration of neurotensin, which is a neuromodulator of dopamine transmission, induced miosis in the rabbit eye (Hernandez and Jennes, 1990). We found that heterozygotes for DRD2 rs6277 SNP showed higher T75 values and Gly/Gly homozygotes for DRD3 rs6280 SNP showed lower MCV values. ARI is a partial agonist for dopamine D2 and D3 receptors (Burris et al., 2002). Based on our previous results, we concluded that ARI effects on the pupil are conceivably due to its antagonism at serotonin receptors. However, as we found a relationship between dopamine receptor genes and MCV and T75 values, presumably the mechanism is more complex and further studies are needed to confirm our findings.

We found that TT subjects of HTR2A rs6313 polymorphism showed higher MCV and MAX values and carriers of T allele of HTR2C rs3813929 showed higher T75 value. Serotonin receptors, in particular the 5-HTlA subtype, may be associated with the iris sphincter muscle and suggest their involvement in the regulation of pupil size (Barnett and Osborne, 1993b). This notion was further strengthened by the finding that pupil size is decreased by the intravenous injection of ketanserin, which is an antagonist primarily of 5-HT2 receptors (Krootila et al., 1987). ARI has agonist activity at 5-HT1A receptors 
and antagonist activity at 5-HT2A receptors, therefore, the polymorphisms in these genes may have a role in showing distinct pupil phenotypes in response to the drug.

\section{Pharmacokinetics and polymorphisms}

Our study confirms the impact of CYP2D6 phenotypes on ARI pharmacokinetics (Hendset et al., 2007; Suzuki et al., 2014). In our previous study, the $\mathrm{AUC}_{0-\mathrm{t}}$ of $\mathrm{ARI}$ was increased by $20 \%$ in IM and by 50\% in PM compared to EM (Belmonte et al., 2018). In the current analysis, we obtained matching results as CYP2D6 IM showed higher AUC (32\%), $\mathrm{C}_{\max }(26 \%)$ and $\mathrm{T}_{1 / 2}(42 \%)$ values than EM. Based on these results, a dose reduction could be recommended for IM, but U.S. Food \& Drug Administration (FDA) only recommends it for PM, a phenotype which we did not find among our subjects (Abilify, Otsuka Pharmaceutical, Co., Ltd., 2014).

To date, there are no consistent findings about the role of polymorphisms in $A B C B 1$. In our previous study, we showed that C1236T SNP has an influence on the pharmacokinetics of ARI, which could be caused by the lower P-gp activity of T/T subjects (Belmonte et al., 2018). In a study performed in pediatric patients, an effect of both polymorphisms was revealed on ARI pharmacokinetics as subjects with the 2677TT and 3435TT genotypes had lower ARI concentrations (Rafaniello et al., 2017). On the contrary, we found that $\mathrm{T}$ allele carriers of $\mathrm{C} 3435 \mathrm{~T}$ polymorphism showed greater AUC values. To date, there are no consistent results about the role of $A B C B 1$ polymorphisms; therefore, further studies should be performed before dose adjustments.

\section{Study limitations}

The main limitation of our study is the low sample size, as only 32 healthy subjects were included. Therefore, it is important to interpret these results with caution. This could be the reason why we could not find PM and UM phenotypes for CYP2D6. 
Studies including more subjects are necessary to increase the statistical reliability of the results. Moreover, we administered single-dose of ARI, which prevents us to assess longer-term effects on the pupil. Furthermore, pharmacokinetic and pharmacogenetic effects on pupillometry could be different in psychotic patients receiving long-term treatment compared to healthy volunteers. Therefore, we are not able to apply pupillometry as a tool to assess autonomic dysfunction in a clinical setting yet, further studies are needed.

\section{Conclusions}

ARI administration produced pupil constriction: MAX, MIN, MCV and T75 parameters were decreased to the peak value when ARI reached $\mathrm{C}_{\max }$. Additionally, effects of ARI on pupillometric parameters are associated with polymorphisms in serotonin (HTR2A and HTR2C) and dopamine (DRD2 and DRD3) receptor genes. Pharmacokinetics of $\mathrm{ARI}$ is affected by sex as $\mathrm{Vd} / \mathrm{F}$ was higher, and $\mathrm{Cl} / \mathrm{F}$ was lower in women than in men. Moreover, CYP2D6 phenotypes had an impact on AUC, $\mathrm{C}_{\max }$ and $\mathrm{T}_{1 / 2}$ of aripiprazole. Additionally, $A B C B 1$ polymorphisms were associated with $\mathrm{T}_{1 / 2}$ and AUC values. In conclusion, pupillometry could be an important and useful tool to assess the autonomic nervous system activity during antipsychotic drug treatment. It could estimate the subclinical signs of adverse effects, therefore predicting them beforehand. Furthermore, the main advantage of these measurements is their non-invasive character.

\section{Funding statement}

D. Koller is co-financed by the H2020 Marie Sklodowska-Curie Innovative Training Network 721236 grant. M. Saiz-Rodríguez and P. Zubiaur are co-financed by Consejería de Educación, Juventud y Deporte from Comunidad de Madrid and Fondo Social Europeo. 


\section{Declaration of conflicting interests}

F. Abad-Santos and D. Ochoa have been consultants or investigators in clinical trials sponsored by the following pharmaceutical companies: Abbott, Alter, Chemo, Cinfa, FAES, Farmalíder, Ferrer, GlaxoSmithKline, Galenicum, Gilead, Janssen-Cilag, Kern, Normon, Novartis, Servier, Silverpharma, Teva, and Zambon. The remaining authors declare no conflicts of interest.

The authors are grateful to the volunteers as well as the effort of the staff of the Clinical Trial Unit of Hospital Universitario de la Princesa.

\section{References}

Abilify, Otsuka Pharmaceutical, Co., Ltd., 2014. Food and Drug Administration. Aripiprazole label. Available at:

http://www.accessdata.fda.gov/drugsatfda_docs/label/2014/021436s038, 021713s030,021729s022,021866s023lbl.pdf.

Alves, T.M., Pereira, J.C.R., Elkis, H., 2005. The psychopathological factors of refractory schizophrenia. Rev. Bras. Psiquiatr. Sao Paulo Braz. 1999 27, 108-112. https://doi.org//S1516-44462005000200007

Barnett, N.L., Osborne, N.N., 1993a. The presence of serotonin (5-HT1) receptors negatively coupled to adenylate cyclase in rabbit and human iris-ciliary processes. Exp. Eye Res. 57, 209-216. https://doi.org/10.1006/exer.1993.1116

Barnett, N.L., Osborne, N.N., 1993b. The effect of serotonin on the rabbit isolated iris sphincter muscle. Curr. Eye Res. 12, 665-673.

Belmonte, C., Ochoa, D., Román, M., Cabaleiro, T., Talegón, M., Sánchez-Rojas, S.D., AbadSantos, F., 2016. Evaluation of the Relationship Between Pharmacokinetics and the Safety of Aripiprazole and Its Cardiovascular Effects in Healthy Volunteers. J. Clin. Psychopharmacol. 36, 608-614. https://doi.org/10.1097/JCP.0000000000000577

Belmonte, C., Ochoa, D., Román, M., Saiz-Rodríguez, M., Wojnicz, A., Gómez-Sánchez, C.I., Martín-Vilchez, S., Abad-Santos, F., 2018. Influence of CYP2D6, CYP3A4, CYP3A5 and $A B C B 1$ polymorphisms on pharmacokinetics and safety of aripiprazole in healthy volunteers. Basic Clin. Pharmacol. Toxicol. https://doi.org/10.1111/bcpt.12960

Burris, K.D., Molski, T.F., Xu, C., Ryan, E., Tottori, K., Kikuchi, T., Yocca, F.D., Molinoff, P.B., 2002. Aripiprazole, a novel antipsychotic, is a high-affinity partial agonist at human dopamine D2 receptors. J. Pharmacol. Exp. Ther. 302, 381-389. 
Chen, S.-F., Shen, Y.-C., Chen, C.-H., 2009. HTR2A A-1438G/T102C polymorphisms predict negative symptoms performance upon aripiprazole treatment in schizophrenic patients. Psychopharmacology (Berl.) 205, 285-292. https://doi.org/10.1007/s00213009-1538-z

Costagliola, C., Parmeggiani, F., Semeraro, F., Sebastiani, A., 2008. Selective Serotonin Reuptake Inhibitors: A Review of its Effects on Intraocular Pressure. Curr. Neuropharmacol. 6, 293-310. https://doi.org/10.2174/157015908787386104

Cumurcu, T., Keser, S., Cumurcu, B.E., Gunduz, A., Kartalci, S., 2015. Refraction and eye anterior segment parameters in schizophrenic patients. Arq. Bras. Oftalmol. 78, 180184. https://doi.org/10.5935/0004-2749.20150046

de Bartolomeis, A., Tomasetti, C., lasevoli, F., 2015. Update on the Mechanism of Action of Aripiprazole: Translational Insights into Antipsychotic Strategies Beyond Dopamine Receptor Antagonism. CNS Drugs 29, 773-799. https://doi.org/10.1007/s40263-0150278-3

de Leon, J., Armstrong, S.C., Cozza, K.L., 2006. Clinical guidelines for psychiatrists for the use of pharmacogenetic testing for CYP450 2D6 and CYP450 2C19. Psychosomatics 47, 75-85. https://doi.org/10.1176/appi.psy.47.1.75

Dean, L., 2012a. Aripiprazole Therapy and CYP2D6 Genotype, in: Pratt, V., McLeod, H., Dean, L., Malheiro, A., Rubinstein, W. (Eds.), Medical Genetics Summaries. National Center for Biotechnology Information (US), Bethesda (MD).

Dean, L., 2012b. Codeine Therapy and CYP2D6 Genotype, in: Pratt, V., McLeod, H., Dean, L., Malheiro, A., Rubinstein, W. (Eds.), Medical Genetics Summaries. National Center for Biotechnology Information (US), Bethesda (MD).

Fliegert, F., Kurth, B., Göhler, K., 2005. The effects of tramadol on static and dynamic pupillometry in healthy subjects--the relationship between pharmacodynamics, pharmacokinetics and CYP2D6 metaboliser status. Eur. J. Clin. Pharmacol. 61, 257-266. https://doi.org/10.1007/s00228-005-0920-y

Fotiou, F., Fountoulakis, K.N., Tsolaki, M., Goulas, A., Palikaras, A., 2000. Changes in pupil reaction to light in Alzheimer's disease patients: a preliminary report. Int. J. Psychophysiol. Off. J. Int. Organ. Psychophysiol. 37, 111-120.

Gaedigk, A., Sangkuhl, K., Whirl-Carrillo, M., Klein, T., Leeder, J.S., 2017. Prediction of CYP2D6 phenotype from genotype across world populations. Genet. Med. Off. J. Am. Coll. Med. Genet. 19, 69-76. https://doi.org/10.1038/gim.2016.80

Gaedigk, A., Simon, S.D., Pearce, R.E., Bradford, L.D., Kennedy, M.J., Leeder, J.S., 2008. The CYP2D6 activity score: translating genotype information into a qualitative measure of phenotype. Clin. Pharmacol. Ther. 83, 234-242. https://doi.org/10.1038/sj.clpt.6100406

Granholm, E., Steinhauer, S.R., 2004. Pupillometric measures of cognitive and emotional processes. Int. J. Psychophysiol. Off. J. Int. Organ. Psychophysiol. 52, 1-6. https://doi.org/10.1016/j.ijpsycho.2003.12.001 
Graur, S., Siegle, G., 2013. Pupillary Motility: Bringing Neuroscience to the Psychiatry Clinic of the Future. Curr. Neurol. Neurosci. Rep. 13. https://doi.org/10.1007/s11910-013-03650

Harris, S.C., Cipriano, A., Colucci, S.V., Kapil, R.P., Geoffroy, P., Hopyan, T., Levy-Cooperman, N., 2017. Oral Abuse Potential, Pharmacokinetics, and Safety of Once-Daily, Single-Entity, Extended-Release Hydrocodone (HYD) in Recreational Opioid Users. Pain Med. Malden Mass 18, 1278-1291. https://doi.org/10.1093/pm/pnw208

Hendset, M., Hermann, M., Lunde, H., Refsum, H., Molden, E., 2007. Impact of the CYP2D6 genotype on steady-state serum concentrations of aripiprazole and dehydroaripiprazole. Eur. J. Clin. Pharmacol. 63, 1147-1151. https://doi.org/10.1007/s00228-007-0373-6

Hernandez, D.E., Jennes, L., 1990. Inhibition of neurotensin-induced miosis by blockade of ocular dopamine pathways. J. Ocul. Pharmacol. 6, 31-36.

Islam, M.M., Iqbal, U., Walther, B.A., Nguyen, P.-A., Li, Y.-C.J., Dubey, N.K., Poly, T.N., Masud, J.H.B., Atique, S., Syed-Abdul, S., 2017. Gender-based personalized pharmacotherapy: a systematic review. Arch. Gynecol. Obstet. 295, 1305-1317. https://doi.org/10.1007/s00404-017-4363-3

Jain, S., Siegle, G.J., Gu, C., Moore, C.G., Ivanco, L.S., Jennings, J.R., Steinhauer, S.R., Studenski, S., Greenamyre, J.T., 2011. Autonomic insufficiency in pupillary and cardiovascular systems in Parkinson's disease. Parkinsonism Relat. Disord. 17, 119-122. https://doi.org/10.1016/j.parkreldis.2010.11.005

Keivanidou, A., Fotiou, D., Arnaoutoglou, C., Arnaoutoglou, M., Fotiou, F., Karlovasitou, A., 2010. Evaluation of autonomic imbalance in patients with heart failure: a preliminary study of pupillomotor function. Cardiol. J. 17, 65-72.

Kim, T.-E., Lee, H., Lim, K.S., Lee, S., Yoon, S.-H., Park, K.-M., Han, H., Shin, S.-G., Jang, I.-J., Yu, K.-S., Cho, J.-Y., 2014. Effects of HM30181, a P-glycoprotein inhibitor, on the pharmacokinetics and pharmacodynamics of loperamide in healthy volunteers. Br. J. Clin. Pharmacol. 78, 556-564. https://doi.org/10.1111/bcp.12368

Kirschbaum, K.M., Müller, M.J., Malevani, J., Mobascher, A., Burchardt, C., Piel, M., Hiemke, C., 2008. Serum levels of aripiprazole and dehydroaripiprazole, clinical response and side effects. World J. Biol. Psychiatry Off. J. World Fed. Soc. Biol. Psychiatry 9, 212-218. https://doi.org/10.1080/15622970701361255

Kleinloog, D., Liem-Moolenaar, M., Jacobs, G., Klaassen, E., de Kam, M., Hijman, R., van Gerven, J., 2012. Does olanzapine inhibit the psychomimetic effects of $\Delta^{9}$ tetrahydrocannabinol? J. Psychopharmacol. Oxf. Engl. 26, 1307-1316. https://doi.org/10.1177/0269881112446534

Koike, Y., Kawabe, T., Nishihara, K., Iwane, N., Hano, T., 2016. Effects of azelnidipine and amlodipine on exercise-induced sympathoexcitation assessed by pupillometry in hypertensive patients. Hypertens. Res. Off. J. Jpn. Soc. Hypertens. 39, 863-867. https://doi.org/10.1038/hr.2016.94 
Krootila, K., Uusitalo, H., Palkama, A., 1987. Effect of alpha-adrenergic and serotonergic blockers on the acute irritative response in the rabbit eye. Exp. Eye Res. 45, 721-729.

Kwak, J.-O., Lee, S.H., Lee, G.S., Kim, M.S., Ahn, Y.-G., Lee, J.H., Kim, S.W., Kim, K.H., Lee, M.G., 2010. Selective inhibition of MDR1 (ABCB1) by HM30181 increases oral bioavailability and therapeutic efficacy of paclitaxel. Eur. J. Pharmacol. 627, 92-98. https://doi.org/10.1016/j.ejphar.2009.11.008

Kwon, J.S., Kim, E., Kang, D.-H., Choi, J.S., Yu, K.-S., Jang, I.-J., Shin, S.-G., APLUS study group, 2008. Taq1A polymorphism in the dopamine D2 receptor gene as a predictor of clinical response to aripiprazole. Eur. Neuropsychopharmacol. J. Eur. Coll.

Neuropsychopharmacol. 18, 897-907. https://doi.org/10.1016/j.euroneuro.2008.07.010

Larson, M.D., Kurz, A., Sessler, D.I., Dechert, M., Bjorksten, A.R., Tayefeh, F., 1997. Alfentanil blocks reflex pupillary dilation in response to noxious stimulation but does not diminish the light reflex. Anesthesiology 87, 849-855.

Lawler, C.P., Prioleau, C., Lewis, M.M., Mak, C., Jiang, D., Schetz, J.A., Gonzalez, A.M., Sibley, D.R., Mailman, R.B., 1999. Interactions of the novel antipsychotic aripiprazole (OPC14597) with dopamine and serotonin receptor subtypes. Neuropsychopharmacol. Off. Publ. Am. Coll. Neuropsychopharmacol. 20, 612-627. https://doi.org/10.1016/S0893133X(98)00099-2

Levy-Cooperman, N., McIntyre, G., Bonifacio, L., McDonnell, M., Davenport, J.M., Covington, P.S., Dove, L.S., Sellers, E.M., 2016. Abuse Potential and Pharmacodynamic Characteristics of Oral and Intranasal Eluxadoline, a Mixed $\mu$ - and k-Opioid Receptor Agonist and 8-Opioid Receptor Antagonist. J. Pharmacol. Exp. Ther. 359, 471-481. https://doi.org/10.1124/jpet.116.236547

Loch, A.A., van de Bilt, M.T., Bio, D.S., Prado, C.M. do, de Sousa, R.T., Valiengo, L.L., Moreno, R.A., Zanetti, M.V., Gattaz, W.F., 2015. Epistasis between COMT Val158Met and DRD3 Ser9Gly polymorphisms and cognitive function in schizophrenia: genetic influence on dopamine transmission. Rev. Bras. Psiquiatr. Sao Paulo Braz. 1999 37, 235-241. https://doi.org/10.1590/1516-4446-2014-1553

Lowenstein, O., Loewenfeld, I.E., 1958. Electronic pupillography; a new instrument and some clinical applications. AMA Arch. Ophthalmol. 59, 352-363.

Ma, X., Maimaitirexiati, T., Zhang, R., Gui, X., Zhang, W., Xu, G., Hu, G., 2014. HTR2C polymorphisms, olanzapine-induced weight gain and antipsychotic-induced metabolic syndrome in schizophrenia patients: a meta-analysis. Int. J. Psychiatry Clin. Pract. 18, 229-242. https://doi.org/10.3109/13651501.2014.957705

Mangas-Sanjuan, V., Pastor, J.M., Rengelshausen, J., Bursi, R., Troconiz, I.F., 2016. Population pharmacokinetic/pharmacodynamic modelling of the effects of axomadol and its $\mathrm{O}$ demethyl metabolite on pupil diameter and nociception in healthy subjects. Br. J. Clin. Pharmacol. 82, 92-107. https://doi.org/10.1111/bcp.12921

Marazziti, D., Baroni, S., Picchetti, M., Piccinni, A., Carlini, M., Vatteroni, E., Falaschi, V., Lombardi, A., Dell'Osso, L., 2013. Pharmacokinetics and pharmacodynamics of 
psychotropic drugs: effect of sex. CNS Spectr. 18, 118-127.

https://doi.org/10.1017/S1092852912001010

McDougal, D.H., Gamlin, P.D., 2014. Autonomic Control of the Eye, in: Terjung, R. (Ed.), Comprehensive Physiology. John Wiley \& Sons, Inc., Hoboken, NJ, USA, pp. 439-473. https://doi.org/10.1002/cphy.c140014

McGavin, J.K., Goa, K.L., 2002. Aripiprazole. CNS Drugs 16, 779-786; discussion 787-788.

Moons, T., de Roo, M., Claes, S., Dom, G., 2011. Relationship between P-glycoprotein and second-generation antipsychotics. Pharmacogenomics 12, 1193-1211. https://doi.org/10.2217/pgs.11.55

NeurOptics, Inc., 2010. Neuroptics PLR-200 ${ }^{\mathrm{TM}}$ Pupillometer Instruction Manual.

Ong, G.L., Bruning, H.A., 1981. Dilated fixed pupils due to administration of high doses of dopamine hydrochloride. Crit. Care Med. 9, 658-659.

Pickworth, W.B., Lee, H., Fudala, P.J., 1990. Buprenorphine-induced pupillary effects in human volunteers. Life Sci. 47, 1269-1277.

Piha, S.J., Halonen, J.P., 1994. Infrared pupillometry in the assessment of autonomic function. Diabetes Res. Clin. Pract. 26, 61-66.

Rafaniello, C., Sessa, M., Bernardi, F.F., Pozzi, M., Cheli, S., Cattaneo, D., Baldelli, S., Molteni, M., Bernardini, R., Rossi, F., Clementi, E., Bravaccio, C., Radice, S., Capuano, A., 2017. The predictive value of $A B C B 1, A B C G 2, C Y P 3 A 4 / 5$ and CYP2D6 polymorphisms for risperidone and aripiprazole plasma concentrations and the occurrence of adverse drug reactions. Pharmacogenomics J. https://doi.org/10.1038/tpj.2017.38

Raffa, R.B., Friderichs, E., Reimann, W., Shank, R.P., Codd, E.E., Vaught, J.L., 1992. Opioid and nonopioid components independently contribute to the mechanism of action of tramadol, an "atypical" opioid analgesic. J. Pharmacol. Exp. Ther. 260, 275-285.

Schmittgen, T.D., Livak, K.J., 2008. Analyzing real-time PCR data by the comparative C(T) method. Nat. Protoc. 3, 1101-1108.

Schwartz, J.B., 2003. The influence of sex on pharmacokinetics. Clin. Pharmacokinet. 42, 107121. https://doi.org/10.2165/00003088-200342020-00001

Siepmann, T., Ziemssen, T., Mueck-Weymann, M., Kirch, W., Siepmann, M., 2007. The effects of venlafaxine on autonomic functions in healthy volunteers. J. Clin. Psychopharmacol. 27, 687-691. https://doi.org/10.1097/jcp.0b013e31815a255b

Skarke, C., Jarrar, M., Schmidt, H., Kauert, G., Langer, M., Geisslinger, G., Lötsch, J., 2003. Effects of $A B C B 1$ (multidrug resistance transporter) gene mutations on disposition and central nervous effects of loperamide in healthy volunteers. Pharmacogenetics 13 , 651-660. https://doi.org/10.1097/01.fpc.0000054133.14659.e2

Spiers, A.S., Calne, D.B., 1969. Action of dopamine on the human iris. Br. Med. J. 4, 333-335.

Stip, E., Tourjman, V., 2010. Aripiprazole in schizophrenia and schizoaffective disorder: A review. Clin. Ther. 32 Suppl 1, S3-20. https://doi.org/10.1016/j.clinthera.2010.01.021

Suzuki, T., Mihara, K., Nakamura, A., Kagawa, S., Nagai, G., Nemoto, K., Kondo, T., 2014. Effects of genetic polymorphisms of CYP2D6, CYP3A5, and ABCB1 on the steady-state plasma concentrations of aripiprazole and its active metabolite, dehydroaripiprazole, in 
Japanese patients with schizophrenia. Ther. Drug Monit. 36, 651-655.

https://doi.org/10.1097/FTD.0000000000000070

Taylor, D.M., 2003. Aripiprazole: a review of its pharmacology and clinical use. Int. J. Clin. Pract. 57, 49-54.

Tobin, A.B., Osborne, N.N., 1989. Evidence for the presence of serotonin receptors negatively coupled to adenylate cyclase in the rabbit iris-ciliary body. J. Neurochem. 53, 686-691.

Tobin, A.B., Unger, W., Osborne, N.N., 1988. Evidence for the presence of serotonergic nerves and receptors in the iris-ciliary body complex of the rabbit. J. Neurosci. Off. J. Soc. Neurosci. 8, 3713-3721.

Urichuk, L., Prior, T.I., Dursun, S., Baker, G., 2008. Metabolism of atypical antipsychotics: involvement of cytochrome p450 enzymes and relevance for drug-drug interactions. Curr. Drug Metab. 9, 410-418.

Wojnicz, A., Belmonte, C., Koller, D., Ruiz-Nuño, A., Román, M., Ochoa, D., Abad Santos, F., 2017. Effective phospholipids removing microelution-solid phase extraction LC-MS/MS method for simultaneous plasma quantification of aripiprazole and dehydroaripiprazole: Application to human pharmacokinetic studies. J. Pharm. Biomed. Anal. 151, 116-125. https://doi.org/10.1016/j.jpba.2017.12.049

Wood, M.D., Scott, C., Clarke, K., Cato, K.J., Patel, N., Heath, J., Worby, A., Gordon, L., Campbell, L., Riley, G., Davies, C.H., Gribble, A., Jones, D.N.C., 2006. Pharmacological profile of antipsychotics at monoamine receptors: atypicality beyond 5-HT2A receptor blockade. CNS Neurol. Disord. Drug Targets 5, 445-452.

Yu, Y., Ramage, A.G., Koss, M.C., 2004. Pharmacological studies of 8-OH-DPAT-induced pupillary dilation in anesthetized rats. Eur. J. Pharmacol. 489, 207-213. https://doi.org/10.1016/j.ejphar.2004.03.007

Zhang, J.-P., Lencz, T., Malhotra, A.K., 2010. D2 receptor genetic variation and clinical response to antipsychotic drug treatment: a meta-analysis. Am. J. Psychiatry 167, 763-772. https://doi.org/10.1176/appi.ajp.2009.09040598 

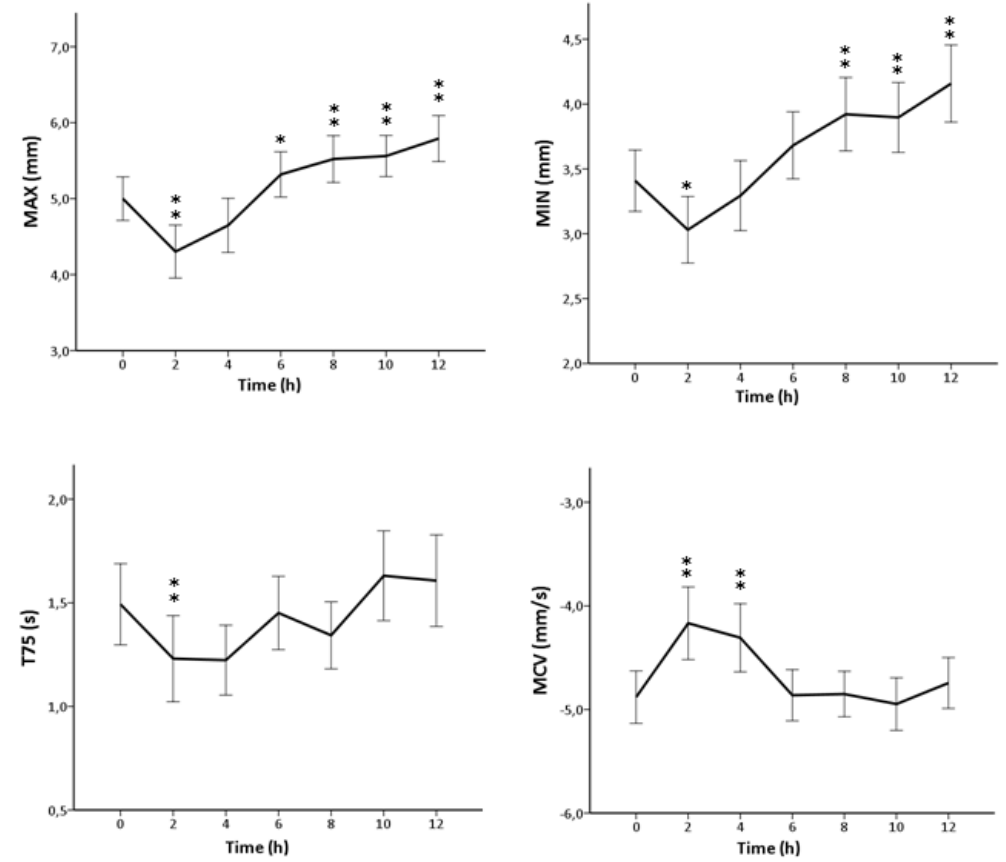

Figure 1. Changes in the pupillometric parameters after administration of aripiprazole 10 mg. Abbreviations: MAX: maximum pupil diameter; MIN: minimum pupil diameter; MCV: maximum constriction velocity; T75: total time taken by the pupil to recover $75 \%$ of the initial resting pupil size. ${ }^{*} \mathrm{p} \leq 0.05$ related to the baseline value. $* * \mathrm{p} \leq 0.001$ related to the baseline value. 

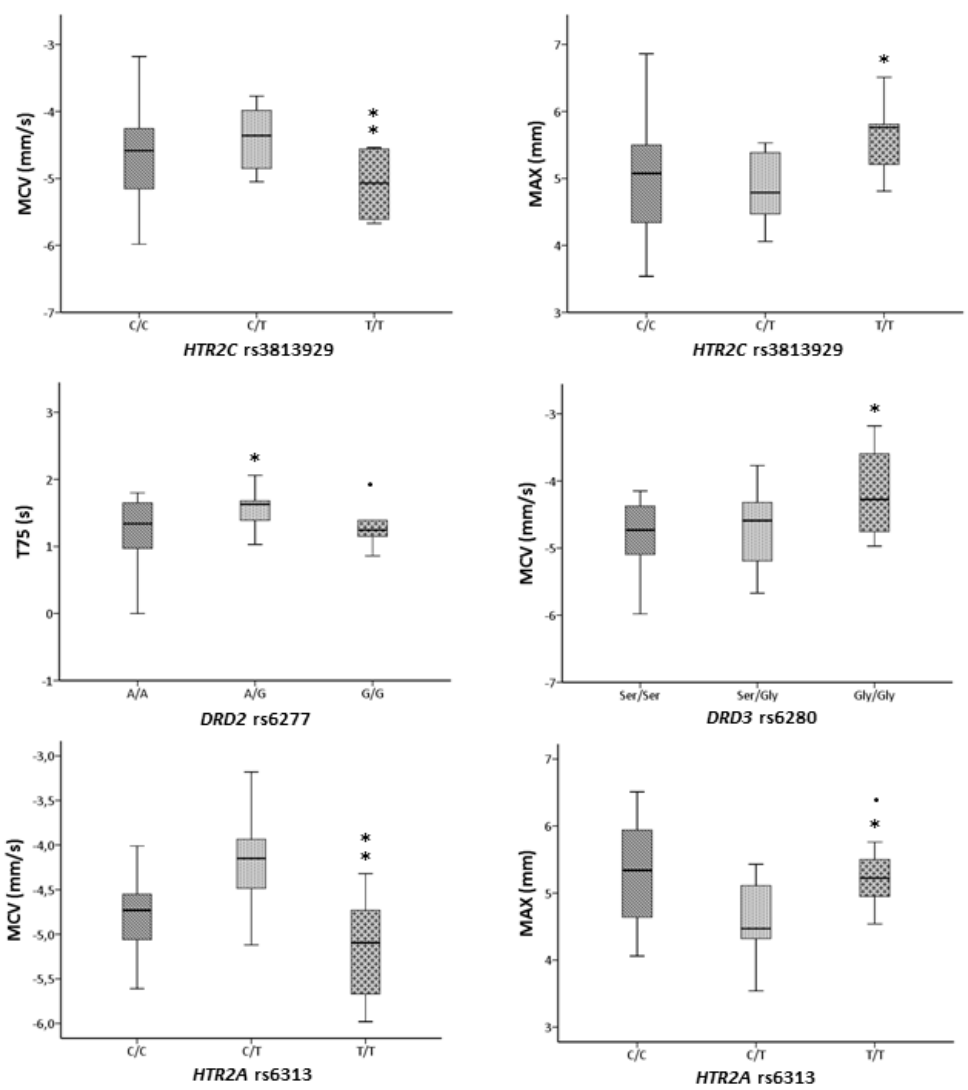

Figure 2. Association of HTR2A rs6313 genotypes with MCV and MAX pupillometric parameters, HTR2C rs3813929 genotypes with MCV and MAX, DRD2 rs6277 genotypes with T75 and DRD3 rs6280 genotypes with MCV. Abbreviations: MCV: maximum constriction velocity; MAX: maximum pupil diameter; T75: total time taken by the pupil to recover $75 \%$ of the initial resting pupil size after it reached the peak of constriction; HTR2A: 5-hydroxytryptamine receptor 2A; HTR2C: 5hydroxytryptamine receptor 2A; DRD2: dopamine D2 receptor; DRD3: dopamine D3 receptor $* \mathrm{p} \leq 0.05 ; * \mathrm{p} \leq 0.001, \cdot$ shows the outliers. 

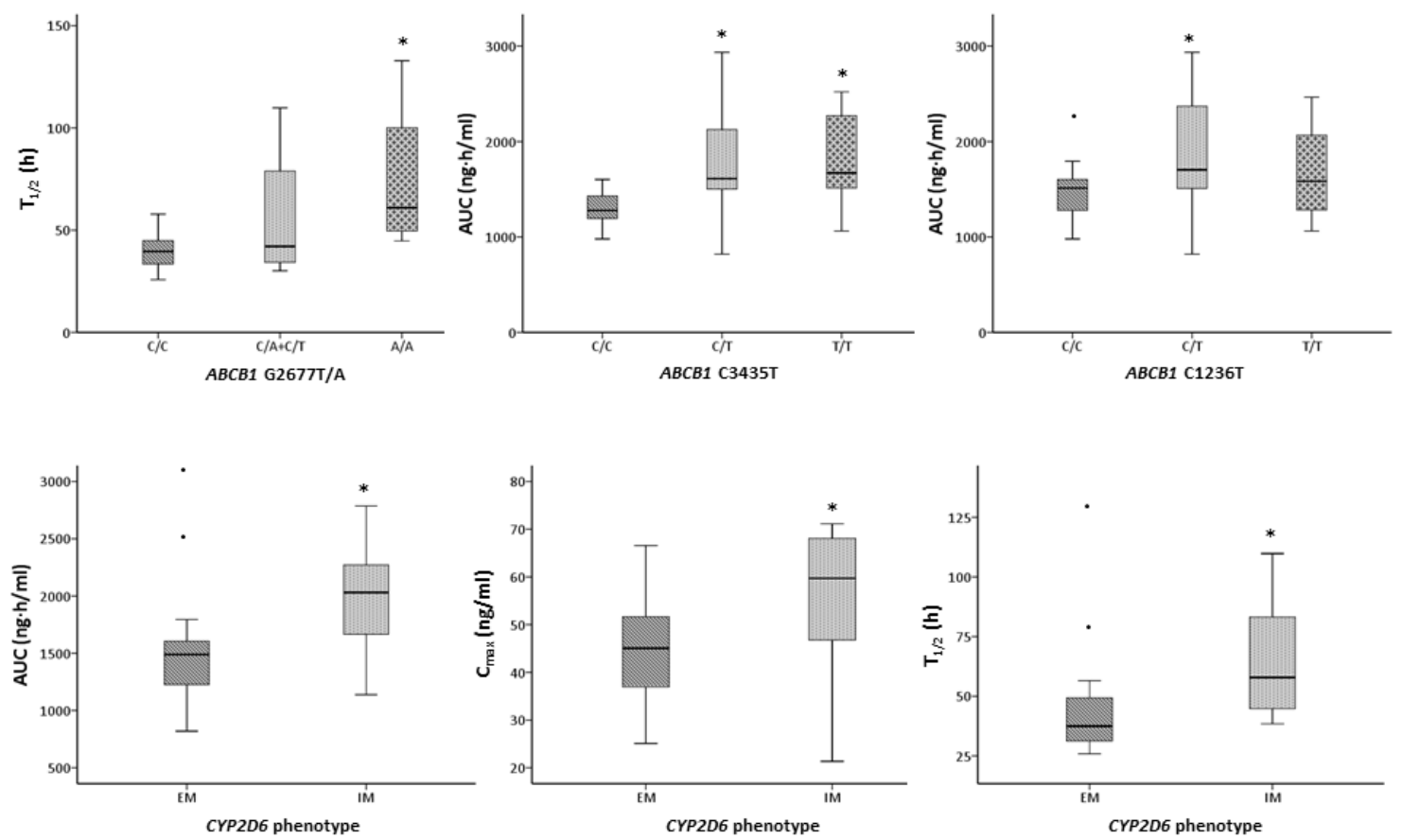

Figure 3. Relationship of CYP2D6 phenotypes (EM, IM) and $A B C B 1$ genotypes (G2677T/A, C3435T, C1236T) with aripiprazole pharmacokinetic parameters $\mathrm{AUC}_{0-72,}$ $\mathbf{C}_{\max }$ and $\mathbf{T}_{1 / 2}$. Abbreviations: $A B C B 1$ : ATP binding cassette subfamily B member 1; CYP: cytochrome p450 oxidase; IM: intermediate metabolizer; EM: extensive metabolizer; $\mathrm{C}_{\max }$ : maximum plasma concentration; $\mathrm{AUC}$ : the total area under the curve; $T_{1 / 2}$ : half-life.

${ }^{*} \mathrm{p} \leq 0.05, \cdot$ shows the outliers. 